\title{
LA COMPETENCIA ESTATAL EN MATERIA DE BECAS Y AYUDAS AL ESTUDIO: FUNDAMENTO Y ALCANCE
}

JOSÉ CANAL MUÑOZ 


\section{SUMARIO}

1. LA FINANCIACIÓN PÚBLICA DE LA ENSEÑANZA REGLADA. 2. EL DERECHO A LA OBTENCIÓN DE AYUDAS AL ESTUDIO. 2.1. NATURALEZA CONSTITUCIONAL O LEGAL DEL DERECHO. 2.2. CONTENIDO Y LÍMITES CONSTITUCIONALES DEL DERECHO. 3. EL SISTEMA ESTATAL DE BECAS Y AYUDAS AL ESTUDIO. 3.1. CONCEPTO Y CARACTERÍSTICAS DE LAS AYUDAS AL ESTUDIO. 3.2. NATURALEZA JURÍDICA DE LAS AYUDAS AL ESTUDIO. 3.2.1. LAS AYUDAS AL ESTUDIO COMO ACTIVIDAD DE FOMENTO. 3.2.2. LAS AYUDAS AL ESTUDIO COMO PRESTACIÓN ECONÓMICA. 4. LA DISTRIBUCIÓN TERRITORIAL DE COMPETENCIAS EN MATERIA DE AYUDAS AL ESTUDIO. 4.1. LA POTESTAD NORMATIVA ESTATAL. 4.2. LAS POTESTADES EJECUTIVAS. 5. SOBRE UNA POSIBLE REVISIÓN DEL FUNDAMENTO Y ALCANCE DE LA COMPETENCIA. 5.1. LA NATURALEZA PRESTACIONAL DE LAS AYUDAS AL ESTUDIO. 5.2. LA REIVINDICACIÓN DE LA REGLA 1. ${ }^{a}$ DEL ART 149.1 DE LA CONSTITUCIÓN. 6. CONCLUSIONES. 


\title{
LA COMPETENCIA ESTATAL EN MATERIA DE BECAS Y AYUDAS AL ESTUDIO: FUNDAMENTO Y ALCANCE
}

\author{
JOSÉ CANAL MUÑOZ
}

\section{LA FINANCIACIÓN PÚBLICA DE LA ENSEÑANZA REGLADA}

La normativa internacional viene insistiendo especialmente en la necesidad de garantizar a todos los ciudadanos el acceso a la educación en condiciones de igualdad. ${ }^{2}$ El cumplimiento de este compromiso requiere de los poderes públicos la remoción de cualquier obstáculo que dificulte o impida el ejercicio de este derecho fundamental, lo que pasa habitualmente por garantizar la provisión de los fondos públicos destinados a sufragar, con mayor o menor intensidad, los costes asociados, directa o indirectamente, a la prestación de los servicios educativos.

De este modo, la educación se concibe en todos los países de la OCDE como un servicio público, en la medida en que su prestación está financiada de forma mayoritaria (y en algunas etapas prácticamente exclusiva) con recursos públicos. De hecho, el problema fundamental de la enseñanza reside no tanto en el puro reconocimiento formal del derecho de toda persona a la educación, como en proveer los medios necesarios para garantizar la adecuada prestación del servicio. Coincidimos con VILLAR

${ }^{1}$ Cuerpo Superior de Administradores Civiles del Estado. Doctor en Derecho en el Programa de Doctorado en Unión europea. Escuela Internacional de Doctorado de la Universidad Nacional de Educación a Distancia. Calle Bravo Murillo, 38. 28015.

${ }^{2}$ El derecho a la educación ocupa un lugar primordial en Naciones Unidas, lo que queda reflejado en diversos instrumentos internacionales de derechos humanos.

La Declaración Universal de Derechos Humanos de 1948 (DUDH) proclama que «Toda persona tiene derecho a la educación».

El Pacto Internacional de Derechos Económicos, Sociales y Culturales de 1966 (PIDESC) dedica los artículos 13 y 14 al derecho a la educación.

La Convención sobre los Derechos del Niño de 1989 (CDN) constituye el primer tratado que reconoce estos derechos con fuerza coercitiva para todos los Estados que lo ratifiquen, ya que la Declaración de 1959 tenía un carácter meramente programático. 
en que la financiación efectiva de un sistema educativo es lo que podrá dar la medida de la posibilidad de ejercer este derecho fundamental transformándolo en algo realmente operativo. ${ }^{3}$

Desde una perspectiva estrictamente jurídica, y centrándonos ya en el ordenamiento español, la aportación de recursos públicos a la financiación de la enseñanza se instrumenta a través de dos instituciones: la gratuidad de la enseñanza obligatoria y las ayudas a las familias. Una primera aproximación podría llevarnos a concluir que ambos instrumentos son alternativos y se utilizan, respectivamente, en las etapas obligatorias y no obligatorias. Sin embargo, se trata de una conclusión precipitada y un análisis más profundo y sosegado del ámbito de aplicación de la garantía constitucional de gratuidad de la educación básica nos llevará a matizar esta afirmación.

La garantía de gratuidad de la educación obligatoria refleja una opción del constituyente por un modelo de financiación pública de los servicios en que consiste la educación institucionalizada, de modo que, para sufragar sus costes, no se practicará un sistema de justicia conmutativa entre quien preste el servicio y quien directamente lo usa o reciba, sino un sistema de justicia distributiva, comprometiendo obligatoriamente la solidaridad de todos los ciudadanos en el sostenimiento de las plazas escolares correspondientes, de forma progresiva a través del sistema fiscal. ${ }^{4}$

El debate sobre el alcance de la gratuidad de la enseñanza básica no es nuevo y ya comenzó a plantearse en la década de los ochenta del siglo pasado. FERNÁNDEZ ENGUITA ${ }^{5}$ sintetiza de forma muy acertada sus términos: La opinión pública acepta en general que los costes directos deben ser cubiertos en la enseñanza obligatoria y en la llamada de oferta obligatoria, es decir, que debe estar disponible para alumnos pero no ser impuesta; acepta, asimismo, que los costes de oportunidad sólo sean cubiertos con carácter excepcional, en parte porque están excluidos del periodo obligatorio y son impensables antes del mismo (aunque ni siempre lo han sido ni en todo el mundo lo son), cuando se piensa que su peso puede frustrar las oportunidades de alumnos especialmente motivados o capaces; en medio quedan los costes indirectos, que la legislación y buena parte de la opinión pública contem-

3 VILLAR EZCURRA, José Luis. «El Derecho a la educación como servicio público», Revista de administración pública, n. ${ }^{\circ}$ 88, 1979. Pág. 176.

En el mismo sentido, EMBID señala que el aspecto de la financiación es, en última instancia, el obstáculo (o el pórtico) para la afirmación de los contenidos del derecho a la educación. EMBID IRUJO, Antonio. «El contenido del derecho a la educación», en Revista Española de Derecho Administrativo, n. ${ }^{\circ} 31,1981$. Pág. 671.

${ }^{4}$ MARTÍNEZ LÓPEZ MUÑIZ, José Luis. «La educación en la Constitución española: derechos fundamentales y libertades públicas en materia de enseñanza», en Persona y derecho: Revista de fundamentación de las Instituciones Jurídicas y de Derechos Humanos, n. ${ }^{\circ}$ 6, 1979, monográfico dedicado a: Libertad de Enseñanza. Pág. 261.

${ }^{5}$ FERNANDEZ ENGUITA, Mariano. «Del Derecho incompleto a la Educación: gratuidad escolar, costes indirectos y política educativa». Revista Avances en supervisión educativa, n. ${ }^{\circ} 33$. 2014. Pag.6. 
plan como algo que es responsabilidad de las familias, pero también puede ser objeto de una política asistencial.

De este modo, la gratuidad garantiza la cobertura pública universal de los costes de escolarización en las enseñanzas obligatorias, que se disfrutan sin exigencia de contraprestación económica alguna en los centros docentes sostenidos con fondos públicos. Sin embargo, esta institución no cubre en su integridad los costes indirectos asociados a la enseñanza obligatoria y, en consecuencia, corresponde al Sistema Estatal de becas y ayudas al estudio asegurar la provisión de los bienes y servicios educativos necesarios para el adecuado ejercicio del derecho a la educación a los colectivos que no alcanzasen niveles de renta suficientes para sufragarlos, al menos hasta que se alcance la plena gratuidad de la Educación Básica, reiteradamente demandada por el Defensor del Pueblo. ${ }^{6}$

Dejando al margen este supuesto, la finalidad principal del Sistema Estatal de becas y ayudas al estudio será garantizar la igualdad de todos los ciudadanos en el acceso a la enseñanza no obligatoria, removiendo los obstáculos que la impidan o dificulten, dando de este modo cumplimiento en el ámbito educativo al mandato genérico contenido en el artículo 9.2 de la Constitución. Para ello, este instrumento del sistema educativo deberá proporcionar los bienes y servicios educativos necesarios para el aprovechamiento de la enseñanza reglada a aquellos estudiantes que, por sus circunstancias socioeconómicas, no pudieran afrontar su adquisición.

\section{EL DERECHO A LA OBTENCIÓN DE AYUDAS AL ESTUDIO}

El derecho a la educación consagrado en el artículo 27 de la Constitución comprende el derecho subjetivo de todos los estudiantes a obtener la provisión pública de los bienes y servicios necesarios para el adecuado aprovechamiento de la enseñanza reglada, en el marco del Sistema Educativo. La ausencia de un reconocimiento explícito en este precepto ha provocado un intenso debate doctrinal sobre la existencia y, en su caso, naturaleza y alcance de un eventual derecho subjetivo de los estudiantes a acceder a ayudas educativas.

${ }^{6}$ El Defensor del Pueblo se ha manifestado favorable a la extensión de la gratuidad a todos los costes de la enseñanza obligatoria, que «considera que la gratuidad ha de abarcar a todo el conjunto de actividades y medios que resultan precisos para que los alumnos cursen las enseñanzas correspondientes. No debe perderse de vista que la Constitución no sólo define la enseñanza básica como gratuita, sino también como obligatoria. Y del establecimiento de ese deber constitucional —impuesto a los menores destinatarios de la normaha de deducirse el correlativo deber público de proporcionar todos los medios imprescindibles para que pueda ser cumplido. Y en ello no influye la naturaleza pública o privada de los centros educativos, ya que el dato de referencia es, en todo caso, el de las enseñanzas que se cursen y su carácter obligatorio». DEFENSOR DEL PUEBLO. Estudio sobre la Gratuidad de los Libros de Texto: programas, ayudas, préstamos y reutilización. Madrid, 2013. Pág. 9. 


\subsection{Naturaleza del derecho a obtener ayudas al estudio}

El derecho internacional recoge el firme compromiso de los Estados a aportar los recursos necesarios para asegurar la accesibilidad de todos a la educación no obligatoria. ${ }^{7}$ Para la consecución de este objetivo, se propone abiertamente una progresiva extensión de la gratuidad de la enseñanza secundaria y superior; sin embargo, y hasta que este objetivo se consiga plenamente, también se contempla la adopción de medidas que faciliten la accesibilidad a la enseñanza basadas en la capacidad económica de los alumnos y, de forma expresa, llega a recogerse el compromiso estatal de «implantar un sistema adecuado de becas».

De este modo, se considera que forma parte del contenido de este derecho a la educación, en su configuración internacional, la facultad de exigir al Estado que haga progresivamente accesibles de hecho, a quienes reúnan las debidas condiciones de capacidad, el acceso a los niveles no obligatorios de la enseñanza, empleando para ello los recursos públicos disponibles, al objeto de remediar las carencias económicas que signifiquen una disparidad práctica en las posibilidades de acceso y permanencia en esos niveles. ${ }^{8}$

El Constituyente español no fue tan explícito y, en este sentido, el Tribunal Constitucional afirma tajantemente que no existe en el artículo $27 \mathrm{CE}$ una referencia expresa a un sistema de prestaciones públicas individualizadas. ${ }^{9}$ Consecuentemente, no es posible fundamentar en el texto constitucional pretensiones individuales de obtención de ayudas al estudio, ya que el derecho a la educación no implica ninguna obligación estatal de subvencionar a las familias para hacerlos efectivos. ${ }^{10}$

Sin embargo, a nuestro juicio, la inexistencia de reconocimiento constitucional de un derecho subjetivo a obtener ayudas al estudio no supone la ausencia de compromisos para los poderes públicos en este campo. Amparándonos en la normativa internacional, consideramos que el Constituyente impone a los poderes públicos la ineludible obligación de dotar anualmente en sus presupuestos fondos suficientes para permitir que todas las personas accedan a la educación, básica y no obligatoria, en condiciones de igualdad, removiendo los obstáculos socioeconómicos que lo impidan o dificulten. En esta línea, el Tribunal Constitucional ha acometido un proceso que, de manera muy acertada, $\mathrm{COTINO}^{11}$ ha calificado de fundamentalización del dere-

7 Quizás el texto más explícito y completo en este sentido sea el artículo 13.2 del PIDESC (1996).

${ }^{8}$ MARTÍNEZ LÓPEZ MUÑIZ, José Luis. «La educación en la Constitución española: derechos fundamentales y libertades públicas en materia de enseñanza», en Persona y derecho: Revista de fundamentación de las Instituciones Jurídicas y de Derechos Humanos, $n .{ }^{\circ}$ 6, 1979, monográfico dedicado a: Libertad de Enseñanza. Pág. 266.

9 STC $188 / 2001$, FFJJ 4 y 5.

${ }^{10}$ EMBID IRUJO, Antonio. «El contenido del derecho a la educación», en Revista Española de Derecho Administrativo, n. ${ }^{\circ} 31,1981$. Pág. 680.

${ }^{11}$ COTINO HUESO, Lorenzo. «El Derecho a la educación como derecho fundamental. Especial atención a su dimensión social prestacional». Centro de Estudios Políticos y Constitucionales. Madrid, 2012. Pág. 210 a 212. 
cho al acceso a ayudas y becas y que, en esencia, consiste en incluir este derecho subjetivo dentro del contenido constitucionalmente garantizado del derecho a la educación. Este proceso de conformación de la naturaleza constitucional del derecho a obtener ayudas y becas al estudio no está exento de complejidad jurídica y tiene como pronunciamiento fundamental la STC 188/2001 ${ }^{12}$, que declara que

«El derecho a las becas o ayudas, como resultado de la obligación de los poderes públicos de garantizar el derecho de todos a la educación, se ordena a asegurar su efectividad, pues «en un Estado social de Derecho (artículo 1 CE), que debe promover las condiciones para que la libertad y la igualdad del individuo sea reales y efectivas (artículo 9.2 CE), el libre desarrollo de la personalidad (artículo 10.1 CE), y reconoce el derecho a la educación (artículo 27.1 CE), es evidente que los poderes públicos deben establecer un programa de ayudas al estudio que garantice a los ciudadanos con menos recursos económicos el acceso a la educación. Dentro de este programa de ayudas pueden incluirse... prestaciones económicas en forma de becas (STC 214/1994, de 14 de julio, FJ. 8)».

Es decir, la Constitución impone al legislador una obligación permanente de actuar para alcanzar la igualdad de oportunidades en el terreno educativo ${ }^{13}$ mediante la configuración de un sistema de ayudas dirigido a los niños pertenecientes a las familias de modesta condición económica ${ }^{14}$, pero no predetermina el catálogo de prestaciones que los poderes públicos deben ofrecer a los ciudadanos para cumplir con este deber constitucional ${ }^{15}$, tarea que queda encomendada al legislador orgánico.

\subsection{Contenido y límites constitucionales del derecho}

Como hemos señalado, las becas o ayudas al estudio no vienen directamente mencionadas por el artículo 27 de la Constitución, pero se configuran como una obligación ineludible de los poderes públicos. Ciertamente, el legislador dispone de una amplia discrecionalidad para establecer los requisitos y condiciones necesarias

12 STC 188/2001, de 20 de septiembre, que resuelve un conflicto de competencias promovido por la Generalitat de Cataluña contra una convocatoria de becas realizada por el Ministerio de Educación y Ciencia. FJ. 5.

13 No bastaría para que se entendiera dada la igualdad de oportunidades con la gratuidad de las plazas en los centros públicos. Esta gratuidad implicaría un trato igual para todos los alumnos y la consecución de la igualdad en una sociedad desigual exige, obviamente, un trato estatal también desigual a los alumnos. Este trato desigual se logra mediante las becas u otras ayudas. En general, sobre el principio de igualdad de oportunidades y el control judicial en el otorgamiento de becas puede consultarse MARTÍN-RETORTILLO, Lorenzo. «El genio expansivo del Estado de Derecho: el principio de igualdad de oportunidades como inspirador de la asistencia oficial docente», en Revista de Administración Pública (RAP), n. ${ }^{\circ}$ 47). 1965. Pág. 83 y sigs.

${ }^{14}$ EMBID IRUJO, Antonio. «El contenido del derecho a la educación», en Revista Española de Derecho Administrativo, n. ${ }^{\circ}$ 31, 1981. Pág. 681.

${ }_{15}$ El propio Tribunal Constitucional matiza que se trata de una obligación «sin predeterminación de las prestaciones o medidas que se hayan de emplear a tal fin, puesto que las becas o ayudas no vienen directamente exigidas por aquel precepto constitucional» (STC 188/2001, de 20 de septiembre, FJ. 5). 
para acceder al sistema de becas, pero deberá garantizar que nadie quede excluido de las enseñanzas no obligatorias por razones socioeconómicas.

La legislación orgánica estatal en materia educativa ha recogido abundantes referencias a las ayudas a la educación, que tratamos de exponer a continuación de forma sistematizada, y no necesariamente cronológica.

A nuestro juicio, la norma de cabecera del modelo se recoge en la LODE (1985), que reconoce a los alumnos un derecho básico «a recibir las ayudas y los apoyos precisos para compensar las carencias y desventajas de tipo personal, familiar, económico, social y cultural, especialmente en el caso de presentar necesidades educativas especiales, que impidan o dificulten el acceso y la permanencia en el sistema educativo». ${ }^{16}$

El instrumento esencial para hacer efectiva la igualdad de oportunidades en el acceso a la educación será el denominado Sistema Estatal de Becas y Ayudas al Estudio, que se configura expresamente como uno de los instrumentos con que cuenta el Sistema Educativo Español para la consecución de sus fines. ${ }^{17}$ Nuestra legislación dedica otras dos normas de carácter orgánico para describir este sistema de becas y ayudas al estudio, diferenciando las enseñanzas universitarias ${ }^{18}$ y no universitarias ${ }^{19}$. Del análisis de esta regulación, el Tribunal Constitucional ha concluido la importancia capital de las ayudas al estudio para garantizar el derecho fundamental a la educación, ya que

«(...) tanto la legislación orgánica como la normativa reglamentaria configuran las becas como un elemento nuclear del sistema educativo dirigido a hacer efectivo el derecho a la educación, permitiendo el acceso de todos los ciudadanos a la enseñanza en condiciones de igualdad a través de la compensación de las condiciones socioeconómicas desfavorables que pudieran existir entre ellos, lo que determina que los poderes públicos estén obligados a garantizar su existencia y real aplicación». ${ }^{20}$

Pero además, estas disposiciones orgánicas revisten especial relevancia ya que forman parte del denominado bloque de constitucionalidad, que se define mayoritariamente por la doctrina como el conjunto de normas jurídicas que, junto a la Constitución, deben ser tenidas en cuenta por el órgano al que está atribuido el control de constitucionalidad para determinar la conformidad o disconformidad con la Constitución de las normas que regulen el ejercicio de este derecho. En nuestro ordenamiento jurídico, este parámetro de la legitimidad constitucional tiene su fundamento en el artículo 28 de la Ley Orgánica 2/1979, de 3 de octubre, del Tribunal Constitucional y ha sido desarrollado por la Jurisprudencia del Tribunal Constitucional.

${ }^{16}$ Letra h) del artículo 6.3 de la Ley Orgánica 8/1985, de 3 de julio, reguladora del Derecho a la Educación (LODE).

17 Artículo 2.bis.3.e) Ley Orgánica 2/2006, de 3 de mayo, de Educación, en la redacción dada por la Ley Orgánica 8/2013, de 9 de diciembre, para la Mejora de la Calidad Educativa (LOMCE).

18 Artículo 45 de la Ley Orgánica 6/2001, de 21 de diciembre, de universidades (LOU).

19 Artículo 83 de la Ley Orgánica 2/2006, de 3 de mayo, de Educación (LOE).

20 STC 188/2001, de 20 de septiembre, FJ 4. ${ }^{\circ}$. 
Aunque los preceptos orgánicos reproducidos tienen carácter esencialmente programático, es posible extraer de los ellos algunos principios generales que deberán respetar tanto el legislador ordinario como las Administraciones Públicas al diseñar y gestionar el Sistema estatal de becas y ayudas al estudio:

— La finalidad que deben perseguir las ayudas es asegurar el acceso y la permanencia en el sistema educativo de todos los ciudadanos, removiendo los obstáculos que pudieran dificultarlo. En consecuencia, aunque la extensión e intensidad de las prestaciones están limitadas por las disponibilidades presupuestarias, deben resultar suficientes para que sus beneficiarios puedan atender adecuadamente a los costes privados necesarios para cursar cada enseñanza. En este sentido, COTINO ha apuntado que se ha abierto la puerta al análisis jurisdiccional del examen de si la beca o ayuda permite alcanzar la gratuidad exigida por el artículo $27.4 \mathrm{CE} .^{21}$

- Aunque las ayudas económicas constituyen el eje vertebrador del sistema, no existen impedimentos para incluir en el Sistema prestaciones de otra naturaleza («los apoyos precisos») para garantizar la igualdad de oportunidades.

— La obtención de ayudas en las etapas educativas postobligatorias conlleva la asunción por los beneficiarios de obligaciones de aprovechamiento académico. A sensu contrario, debe interpretarse que estas exigencias no resultan ineludibles en las etapas obligatorias, aunque tampoco se prohíbe el establecimiento de requisitos mínimos de rendimiento académico.

- Aunque no existe una declaración formal expresa, resulta evidente la configuración de las becas y ayudas al estudio como subvenciones y, en consecuencia, se les aplica la consolidada doctrina constitucional sobre distribución de competencias en materia de subvenciones públicas, que será analizada con detalle más adelante.

Estos elementos, directamente derivados del bloque de la constitucionalidad, proporcionan un parámetro objetivo que permite el enjuiciamiento de constitucionalidad de las medidas, normativas o ejecutivas, que adopten los poderes públicos en materia de becas. ${ }^{22}$ Es decir, tanto el Tribunal Constitucional como los tribunales ordinarios podrían declarar la inconstitucionalidad de un sistema de becas que no

21 STS de 4 de julio de 2005. El Tribunal Supremo admite la prueba de la insuficiencia de la ayuda, o que se censurase que «las ayudas no llegaban a facilitar la gratuidad». Finalmente este argumento no fue alegado por el demandante y, en consecuencia, no fue objeto del fallo.

${ }^{22}$ Diferimos en este punto con COTINO, que considera que, «por lo general, las cuestiones que se suscitan respecto a las becas y ayudas al estudio lo son de legalidad ordinaria» y sostiene un alcance restringido del juicio de constitucionalidad del sistema de becas y ayudas, que debe limitarse a los parámetros del derecho a la educación y, de forma complementaría, a comprobar el respeto de otros mandatos constitucionales como la interdicción de la arbitrariedad, la no discriminación o la necesidad de fundamentar las resoluciones administrativas que afecten derechos fundamentales.

COTINO HUESO, Lorenzo. «El Derecho a la educación como derecho fundamental. Especial atención a su dimensión social prestacional». Centro de Estudios Políticos y Constitucionales. Madrid, 2012. Pág. 212. 
pueda atender eficazmente sus fines, ya sea por insuficiencia de recursos presupuestarios, ya por desatender la compensación de costes educativos considerados imprescindibles para asegurar el adecuado aprovechamiento de la enseñanza, ya por excluir a colectivos socio-económicamente desfavorecidos.

Más allá de estos límites constitucionales, cuyo respeto es susceptible de juicio de constitucionalidad, las Administraciones educativas y el Gobierno de la Nación disponen de un amplio margen para modular la política de becas y ayudas al estudio y conciliarlas con otras políticas públicas como la educativa (de la que constituye un elemento esencial), la fiscal (omnipresente en el momento actual), o la social, entre otras.

\section{EL SISTEMA ESTATAL DE BECAS Y AYUDAS AL ESTUDIO}

El instrumento esencial para hacer efectiva la igualdad de oportunidades en la enseñanza es el Sistema Estatal de becas y ayudas al estudio. Sin embargo, la aparente relevancia que el Legislador Orgánico otorga a esta institución, no se corresponde con la atención que recibe en los desarrollos legal y reglamentario, de modo que es preciso abordar una delimitación doctrinal de su concepto y naturaleza.

\subsection{Concepto y características de las ayudas al estudio}

Cualquier aproximación al concepto de ayudas al estudio debe partir del marco jurídico vigente ${ }^{23}$, que define las becas y ayudas como toda cantidad o beneficio económico que se conceda para iniciar o proseguir enseñanzas conducentes a la obtención de títulos oficiales con validez en todo el territorio nacional y que son financiadas con cargo a los Presupuestos Generales del Estado. ${ }^{24}$ En esta definición se contienen las cuatro características que permiten delimitar el alcance de las prestaciones que se comprenden actualmente en el sistema estatal de becas y ayudas al estudio.

- En primer lugar, aunque pudiera parecer una obviedad, el sistema únicamente comprende prestaciones económicas, quedando implícitamente excluida cualquier otro tipo de prestación de diferente naturaleza. Es más, el sistema no comprende cualquier prestación de contenido económico, sino que exige una transferencia de rentas desde los poderes públicos hacia los estudiantes o sus familias.

${ }^{23}$ La normativa básica estatal de rango reglamentario se comprende en el Real Decreto 1721/2007, de 21 de diciembre, por el que se establece el régimen de las becas y ayudas al estudio personalizadas.

${ }^{24}$ Este concepto se construye a partir de las definiciones de becas y ayudas recogidas el artículo 1 del Real Decreto 1721/2007, que en sus cuatro apartados definen, respectivamente, las becas, las ayudas al estudio, las becas y ayudas al estudio territorializadas y las becas y ayudas al estudio no territorializadas. 
- El segundo elemento necesario para determinar la condición de beca y ayuda al estudio es la persecución de la finalidad educativa. Como ya estableció el legislador orgánico, las becas y ayudas al estudio están dirigidas a permitir a los beneficiarios iniciar o proseguir en el sistema educativo, precisándose reglamentariamente lo que podría parecer una obviedad, que las enseñanzas cursadas deben tener carácter reglado y, en consecuencia, conducir a la obtención de títulos oficiales y con validez en todo el territorio nacional.

Este criterio permite excluir del sistema un amplio abanico de becas que financian programas de formación no reglada y otros en los que el componente formativo resulta secundario respecto al objetivo principal, como pueden ser las becas de formación e investigación que convocan periódicamente numerosos organismos públicos. ${ }^{25}$

- En tercer lugar, la inclusión en el Sistema Estatal requiere que las prestaciones se financien con cargo a los Presupuestos Generales del Estado. Tradicionalmente, la financiación de las becas y ayudas al estudio ha procedido de los Presupuestos Generales del Estado, pero actualmente las Comunidades Autónomas cuentan con programas de ayudas propios, complementarios del estatal, financiados con sus propios presupuestos y, además, han adoptado programas de ayudas educativas otras instituciones públicas, como son las universidades y las Administraciones locales, e incluso privadas.

— Finalmente, es preciso indicar que el ámbito de aplicación de la norma básica comprende únicamente las subvenciones que son objeto de concesión directa, por no limitar su convocatoria el número máximo de eventuales beneficiarios; se trata de las becas generales a los alumnos que cursen enseñanzas universitarias y no universitarias, las ayudas a los estudiantes con necesidades específicas de apoyo educativo y las exenciones de matrícula de los estudiantes universitarios miembros de familias numerosas.

A nuestro juicio, esta delimitación del ámbito de aplicación del Real Decreto $1721 / 2007$ resulta excesivamente restrictiva, ya que las ayudas que comprende no agotan las actuaciones del Sistema Educativo que contribuyen a garantizar la igualdad de acceso a la educación, excluyendo prestaciones muy relevantes, tanto de carácter económico (por ejemplo, los préstamos universitarios), como no económico (programas de apoyo a la gratuidad de libros de texto en la enseñanza obligatoria).

25 Por ejemplo, el Ministerio de Educación, Cultura y Deporte ha convocados este tipos de becas para 2015/16 mediante Orden de 17 de febrero de 2016, por la que se convocan becas para la formación e investigación en el Ministerio de Educación, Cultura y Deporte. 


\subsection{Naturaleza jurídica de las ayudas al estudio}

Las Administraciones Públicas desarrollan las tareas que les encomienda el legislador de muy diversas formas, que han tratado de agruparse en diferentes categorías. La clasificación tradicional y que cuenta con mayor aceptación en la doctrina científica distingue entre la actividad de policía o intervención, la actividad de prestación o servicio público y la actividad de fomento. ${ }^{26}$

La categoría en la que deben incluirse las prestaciones comprendidas en el Sistema Estatal de becas y ayudas al estudio ha suscitado debate en la doctrina científica, planteándose la posibilidad de calificarlas, bien como una actividad de fomento, bien como una actividad prestacional. Esta calificación resulta relevante para determinar la naturaleza jurídica de la institución y sus características, que condicionarán su encuadramiento en el ordenamiento jurídico y, en consecuencia, la legislación general y la doctrina constitucional que les será de aplicación. En este sentido, no cabe duda de que las cantidades económicas que se transfieren a los estudiantes constituyen una ayuda pública, pero nuestro ordenamiento ofrece una amplia tipología de ayudas, cada una con un tratamiento jurídico diferenciado.

\subsubsection{Las ayudas al estudio como actividad de fomento}

En sentido amplio, el fomento será cualquier actividad de la Administración encaminada a promover la mejora de cualquier aspecto del nivel material o moral de una nación, cualesquiera que sean los medios utilizados para ello. ${ }^{27}$ En la actividad de fomento se suelen distinguir diversas técnicas, diferenciando entre estímulos honoríficos, jurídicos y económicos. Estos últimos son los más importantes y en ellos se comprenden, tanto las ventajas de carácter real, que suponen una prestación por la Administración a los particulares consistente en el uso o aprovechamiento de un bien de dominio público o la utilización gratuita por el particular de los servicios técnicos de la Administración, como las ventajas de carácter financiero, que pueden consistir bien en que la Administración acuerde un desembolso en favor de determinados sujetos (auxilios directos), o bien en que les exima de obligaciones fiscales (auxilios indirectos).

El auxilio directo más característico es la subvención, que se define en la LGS $(2003)^{28}$ como toda disposición dineraria realizada por cualquiera de las Administraciones públicas, a favor de personas públicas o privadas, y que cumpla los siguientes requisitos:

${ }^{26}$ JORDANA DE POZAS. «Ensayo de una teoría del fomento en el Derecho administrativo», en Revista de Estudios Políticos, n. ${ }^{\circ} .48$.

${ }^{27}$ GIL IBÁÑEZ, José Luis. «El régimen de las becas y ayudas al estudio», en Manuales de formación continuada, n. ${ }^{\circ}$. 16, 2001 (Ejemplar dedicado a: Aspectos administrativos del derecho a la educación: especial consideración de Universidades públicas). Pág. 222.

${ }^{28}$ Artículo 2.1 de la Ley 38/2003, de 17 de noviembre, General de Subvenciones (LGS). 
a) Que la entrega se realice sin contraprestación directa de los beneficiarios.

b) Que la entrega esté sujeta al cumplimiento de un determinado objetivo, la ejecución de un proyecto, la realización de una actividad, la adopción de un comportamiento singular, ya realizados o por desarrollar, o la concurrencia de una situación, debiendo el beneficiario cumplir las obligaciones materiales y formales que se hubieran establecido.

c) Que el proyecto, la acción, conducta o situación financiada tenga por objeto el fomento de una actividad de utilidad pública o interés social o de promoción de una finalidad pública.

El legislador parece haber optado por encuadrar las becas y ayudas al estudio en al ámbito de las subvenciones. Aunque no existe una declaración expresa en este sentido, se trata de una decisión implícita en las disposiciones reguladoras del sistema:

— La LIP (2005) ${ }^{29}$ declara la expresa sujeción de las becas y ayudas al estudio a la legislación de subvenciones, al determinar que su otorgamiento se someterá a la modalidad de concesión directa. ${ }^{30}$ Es cierto que el sometimiento a la legislación general de subvenciones no presupone necesariamente una naturaleza subvencional, ya que existen prestaciones y ayudas públicas incluidas en el ámbito de aplicación de la LGS (2003) que no son subvenciones. ${ }^{31} \mathrm{~A}$ pesar de ello, este hecho constituye un indicio evidente a favor de la calificación legal de las becas y ayudas como subvención.

— El Real Decreto 1721/2007 tampoco recoge la calificación de las becas como subvenciones ni contiene una cláusula general de aplicación supletoria de la ley de subvenciones. Sin embargo, podría apreciarse un reconocimiento implícito de la aplicación, no ya supletoria, sino incluso directa de esta normativa en la expresa exclusión de la aplicación de esta norma a algunos aspectos concretos de la concesión de las becas, como es la posibilidad de obtener la condición de beneficiario aunque no se cumplan los requisitos establecidos en el artículo 13.2 LGS (2003). ${ }^{32}$ La interpretación de este precepto a sensu contrario conduce necesariamente a considerar aplicable la legislación subvencional a los restantes aspectos no expresamente excluidos.

29 Ley 24/2005, de 18 de noviembre, de reformas para el impulso a la productividad (LIP).

30 La disposición adicional novena de la LIP (2005) establece, en su primer párrafo, que

«Las becas y ayudas al estudio que se convoquen con cargo a los Presupuestos del Ministerio de Educación y Ciencia para seguir estudios reglados y para las que no se fije un número determinado de beneficiarios, se concederán de forma directa, al amparo de lo dispuesto en el artículo 22.2.b) de la Ley 38/2003, de 17 de noviembre, General de Subvenciones, a los alumnos de los distintos niveles del sistema educativo, tanto universitario como no universitario.»

31 En este sentido, PASCUAL señala que la LGS (2003) no es una ley de ayudas y que al apartado 4 de su artículo 2 enumera una serie de supuestos, ayudas o prestaciones sociales en su mayor parte, a los que se niega el carácter de subvención. PASCUAL GARCÍA, José. «Régimen jurídico de las subvenciones públicas». Boletín Oficial del Estado. Madrid, 1996. Pág. 51.

32 Artículo 4.5 LGS (2003). 
- Por último, el procedimiento de concesión de las becas y ayudas que se regula en todas las convocatorias anuales se ajusta perfectamente a lo dispuesto en la Ley de subvenciones y en su tramitación se respetan todas las formalidades que en ella se exigen.

Estos argumentos respaldan la posición doctrinal dominante, que considera que la concesión de becas y ayudas al estudio por las distintas Administraciones Públicas debería enmarcarse dentro de la actividad de fomento, en los estímulos económicos como unos auxilios directos (becas), participando de la naturaleza y características de las subvenciones y, en algunos casos, como auxilios indirectos (por ejemplo, exención del pago del importe de la matrícula). ${ }^{33}$

\subsubsection{Las ayudas al estudio como prestación económica}

Frente a la posición anterior, podría sostenerse que el Sistema estatal de becas y ayudas al estudio forma parte del contenido prestacional del derecho a la educación.

El derecho de todos a la educación incorpora, junto a su contenido primario de derecho de libertad, una dimensión de prestación, en cuya virtud los poderes públicos habrán de procurar la efectividad de tal derecho y hacerlo, para los niveles básicos de la enseñanza, en las condiciones de obligatoriedad y gratuidad que demanda el apartado 4 de este artículo 27 de la Norma Fundamental. Para garantizar el derecho de todos a la educación, los poderes públicos disponen de un instrumento esencial: la «programación general de la enseñanza, con participación efectiva de todos los sectores afectados» (artículo 27.5 CE). Esta potestad de programación general de la enseñanza está expresamente atribuida a la Administración General del Estado. ${ }^{34}$

Resulta complejo identificar las facultades públicas concretas en las que se descompone esta potestad general de programación, habiendo apuntado la doctrina científica al menos dos: la organización de los contenidos de los programas exigibles para cada nivel educativo de la enseñanza reglada (obligatoria o no obligatoria), y el relativo a la previsión y organización de los puestos escolares necesarios para hacer posible el ejercicio efectivo del derecho a la educación en libertad. ${ }^{35}$ La organización de los contenidos se realiza a través de los instrumentos normativos que configuran el currículo de las diferentes enseñanzas. La programación de los puestos escolares,

${ }^{33}$ GIL IBÁÑEZ, José Luis. «El régimen de las becas y ayudas al estudio», en Manuales de formación continuada, n. ${ }^{\circ}$. 16, 2001 (Ejemplar dedicado a: Aspectos administrativos del derecho a la educación: especial consideración de Universidades públicas). Pág. 224.

${ }^{34}$ Letra b) del apartado 2 de la disposición adicional primera de la Ley Orgánica 8/1985, de 3 de julio, reguladora del Derecho a la Educación.

${ }^{35}$ DE LOS MOZOS TOUYA, Isabel María. «Programación y Libertad Escolar: Incidencia en el otorgamiento y denegación de conciertos, aumento y reducción de unidades concertadas», en REQUERO IBAÑEZ, José Luis y MARTÍNEZ LÓPEZ MUÑIZ, José Luis. Los Derechos Fundamentales en la Educación. Consejo General del Poder Judicial. Madrid, 2008 
por su parte, pretende conciliar los intereses de la oferta escolar y de la demanda educativa $^{36}$ y puede vincularse a al artículo 109 LOE, genéricamente referido a la «Programación de la red de centros».

Pues bien, el Tribunal Constitucional incluye una tercera dimensión a la programación general de la enseñanza, que no es otra que un sistema de becas que permita el acceso de todos los ciudadanos a la enseñanza en condiciones de igualdad a través de la compensación de las condiciones socioeconómicas desfavorables que pudieran padecer. $^{37}$

\section{LA DISTRIBUCIÓN TERRITORIAL DE COMPETENCIAS EN MATERIA DE AYUDAS AL ESTUDIO}

A los efectos de la delimitación territorial de competencias, las becas y ayudas al estudio han sido habitualmente incluidas dentro de la materia educativa. En este sentido, es loable el esfuerzo sistemático acometido por la Ley Orgánica 6/2006, de 19 de julio, de reforma del Estatuto de Autonomía de Cataluña (EAC 2010), posteriormente recogido en otros Estatutos, que incluye a las becas y ayudas al estudio como una submateria concreta dentro de la enseñanza universitaria y no universitaria, sobre las que las Comunidades Autónomas ostentan competencias exclusivas o compartidas, según se financien con fondos propios o estatales. ${ }^{38}$ En todo caso, debe advertirse que esta disposición contribuye a clarificar la ubicación sistemática de la materia ${ }^{39}$, pero no modifica la aplicación en la doctrina constitucional sobre distribución de competencias. ${ }^{40}$

La actividad estatal en materia de becas y ayudas al estudio ha suscitado una intensa conflictividad competencial con las Comunidades Autónomas, que ha permitido generar un sólido cuerpo doctrinal sobre su régimen de distribución de competencias. En 2001, un primer y esencial pronunciamiento del Tribunal Constitucional acordó aplicar a esta institución la doctrina general sobre subvenciones estatales ${ }^{41}$;

36 FERNÁNDEZ-MIRANDA Y CAMPOAMOR, Alfonso, «El derecho a la educación y la libertad de enseñanza en el mercado educativo», en Escolarización del alumnado en el sistema educativo español: cuestiones jurídicas. Fundación Europea Sociedad y Educación. Madrid, 2006. pág. 37-65.

37 En este sentido, STC 188/2001, de 20 de septiembre, FJ 5.

38 Apartados 2 y 3 del artículo 131 del Estatuto de Autonomía de Cataluña (2010).

39 Aunque el EAC (2010) ha sido ampliamente cuestionado desde la perspectiva de su adecuación al marco constitucional, es justo reconocerle un singular esfuerzo desde la perspectiva de la técnica jurídica, que conduce a una sistematización de las materias y submaterias sobre las que se asienta el régimen de distribución de competencias que, en términos generales, responde a los pronunciamientos del Tribunal Constitucional. Las críticas de constitucionalidad en este punto del Estatuto no se han referido a la sistematización de las materias y submaterias, sino a la delimitación del alcance de las potestades legislativas y ejecutivas que se proyectan sobre ellas.

40 Así lo estableció la STC 31/2010. En este mismo sentido, la STC 137/2010, en su FJ 52.

41 STC 188/2001, de 20 de septiembre de 2001. 
revelador de la intensidad del debate interno que precedió a esta decisión fue el hecho de que se formulasen tres votos particulares a la sentencia aprobada por la mayoría. ${ }^{42}$

Los sucesivos pronunciamientos del Tribunal Constitucional sobre esta materia (Sentencias 212/2005, 25/2015 y STC 95/2016) han permitido construir una amplia doctrina que parte de la consideración de las becas y ayudas al estudio como subvenciones públicas en materia educativa, lo que determina que la competencia estatal se encuentre ubicada en el segundo de los supuestos propuestos. ${ }^{43}$

Partiendo de esta premisa, resulta capital identificar el título que fundamenta la competencia estatal, planteándose como dos únicas alternativas las reglas $1 .^{\mathrm{a}}$ y $30{ }^{\mathrm{a}}$ del artículo 149.1 de la Constitución que, reservan al Estado, respectivamente, la regulación de «las condiciones básicas que garanticen la igualdad de todos los españoles en el ejercicio de los derechos y en el cumplimiento de los deberes constitucionales» y de las «normas básicas para el desarrollo del artículo 27 de la Constitución, a fin de garantizar el cumplimiento de las obligaciones de los poderes públicos en esta materia». Esta decisión es especialmente relevante, por cuanto determina el alcance de la competencia estatal, y suscitó un intenso debate en el seno del Tribunal Constitucional, zanjado con la decisión mayoritaria de invocar la regla $30 .^{a}$ del artículo 149.1 de la Constitución, de modo que el Estado ostenta en materia de becas y ayudas al estudio competencias normativas de carácter básico y sólo de forma excepcional podría asumir funciones ejecutivas.

Esta doctrina constitucional sobre distribución de competencias ha sido acogida por la legislación orgánica vigente, que describe las funciones que corresponden al

${ }^{42}$ El primer voto particular fue formulado por el Magistrado don Carlos Viver Pi-Sunyer. El segundo voto particular fue formulado por el Magistrado don Vicente Conde Martín de Hijas, al que se adhirieron los Magistrados don Manuel Jiménez de Parga y Cabrera y don Fernando Garrido Falla. El tercer voto particular fue formulado por el Magistrado don Guillermo Jiménez Sánchez.

${ }^{43}$ En principio y de acuerdo con la doctrina del Tribunal Constitucional sistematizada en la Sentencia 13/1992 es posible distinguir cuatro supuestos generales de delimitación de competencias entre Estado y Comunidades Autónomas en lo que se refiere al ejercicio de la actividad subvencional, que ordenamos de menor a mayor intensidad de las potestades estatales:

- Un primer supuesto se produce cuando la Comunidad Autónoma ostenta una competencia exclusiva sobre una determinada materia y el Estado no invoca título competencial alguno, genérico o específico, sobre la misma.

- El segundo supuesto se da cuando el Estado ostenta un título competencial genérico de intervención que se superpone a la competencia de las Comunidades Autónomas sobre una materia, aun si ésta se califica de exclusiva, o bien tiene competencia sobre las bases o la coordinación general de un sector o materia, correspondiendo a las Comunidades Autónomas las competencias de desarrollo normativo y de ejecución.

- Un tercer supuesto es aquel en que el Estado tiene atribuida la competencia sobre la legislación relativa a una materia, mientras que corresponde a la Comunidad Autónoma la competencia de ejecución.

- Como excepción a los supuestos anteriores, el cuarto supuesto es aquél en que el Tribunal admite una gestión centralizada de los fondos presupuestados (a pesar de tener las Comunidades Autónomas competencias ejecutivas sobre la materia) cuando el Estado ostente algún título competencial, genérico o específico, y concurran determinadas circunstancias excepcionales. 
Gobierno de la Nación en relación con el sistema de becas y ayudas al estudio financiado con cargo a los Presupuestos Generales del Estado.

El Tribunal Constitucional ha venido manteniendo una posición que podríamos calificar de equilibrada en la determinación del reparto de competencias en esta materia. Por un lado, se viene mostrando generoso con el Estado en la delimitación del alcance de la potestad normativa básica, a la que reconoce un amplio margen regulatorio; por otra parte, afirma categóricamente el carácter autonómico de las funciones ejecutivas, adoptando un criterio enormemente restrictivo para su eventual centralización.

\subsection{La potestad normativa estatal en materia de ayudas al estudio.}

La identificación de la regla 30. ${ }^{a}$ del artículo 149.1 CE como fundamento de la competencia estatal supone la circunscripción de las potestades estatales al ámbito normativo, de forma compartida con las Comunidades Autónomas. Efectivamente, se reconoce al Estado una competencia legislativa básica que le permite

«consignar subvenciones de fomento en sus Presupuestos Generales, especificando su destino y regulando sus condiciones esenciales de otorgamiento hasta donde lo permita su competencia genérica, básica o de coordinación» debiendo precisar abora que, en relación con las becas, dichas condiciones esenciales de otorgamiento pueden alcanzar hasta donde sea imprescindible "para garantizar el cumplimiento por los poderes públicos de sus deberes en esta materia» (artículo 149.1.30. ${ }^{\circ} \mathrm{CE}$ ), y resulte necesario para conseguir la finalidad deseada y garantizar una politica educativa homogénea para todo el territorio nacional, sin desconocer las competencias normativas y de ejecución de las Comunidades Autónomas».

Conforme a la asentada doctrina constitucional, esta potestad normativa básica debe dejar un margen a las Comunidades Autónomas para concretar con mayor detalle su afectación o destino o, al menos, para desarrollar o complementar la regulación de las condiciones de otorgamiento de las ayudas y su tramitación.

Como resulta habitual en relación con las competencias compartidas, el alcance material de la normativa básica estatal constituye uno de los aspectos cuya precisa delimitación ha demandado mayores esfuerzos al Tribunal Constitucional. En aplicación de la doctrina constitucional, el Gobierno aprobó el Real Decreto 1721/2007 que, junto con los reales decretos que establecen anualmente los umbrales de renta y patrimonio familiar, determina que la potestad normativa básica del Estado se extienda a cualquier factor que sea preciso para asegurar la igualdad en el acceso. La implicación en este ámbito del derecho fundamental a la educación constituye un argumento decisivo para justificar una especial intensidad de la potestad normativa estatal a fin de garantizar al máximo la homogeneidad del sistema y un importante grado de unidad en el disfrute de estas ayudas.

No obstante, esta generosa extensión del alcance material de la regulación estatal ha suscitado el reproche de varias Comunidades Autónomas, que consideran vulne- 
radas sus competencias normativas, posición que ha sido recogida en el voto particular de algún Magistrado discrepante con la posición mayoritaria. ${ }^{44}$

En lo que podría interpretarse como un intento de acoger parcialmente esta línea argumental minoritaria y prevenir futuras controversias, a partir del curso 2008/2009 45 se reconoció a las Comunidades Autónomas la posibilidad de conveniar con el Ministerio la cofinanciación de las becas que se concedieran a estudiantes con rentas familiares inferiores a un umbral de renta que la Comunidad Autónoma puede determinar dentro de una horquilla establecida con carácter básico. De este modo se ampliaba la potestad normativa de las administraciones educativas, que podrían adaptar los umbrales de renta comunes a sus peculiaridades socioeconómicas, aunque asumiendo con cargo a sus presupuestos los costes adicionales que pudieran conllevar estas decisiones.

\subsection{Las potestades ejecutivas}

La segunda consecuencia ineludiblemente asociada a la invocación del artículo 149.1.30. ${ }^{a}$ de la Constitución es el reconocimiento de que las competencias de ejecución y gestión de las becas corresponderán exclusivamente a las Comunidades Autónomas, «salvo que la naturaleza de la medida haga imprescindible la gestión directa y centralizada para asegurar su plena efectividad dentro de la ordenación básica del sector, para garantizar iguales posibilidades de obtención y disfrute por parte de sus potenciales destinatarios en todo el territorio nacional o, por último, cuando dicha centralización sea un medio necesario para evitar que se sobrepase la cuantía global de los fondos destinados a la subvención. En todo caso, la necesidad de la gestión centralizada debe aparecer razonablemente justificada o deducirse sin esfuerzo de la naturaleza y contenido de la medida de fomento de que se trate». ${ }^{46}$

El Tribunal Constitucional se ha mostrado claramente restrictivo en el reconocimiento al Ministerio de Educación de funciones ejecutivas sobre los programas de becas y ayudas financiados con cargo a los Presupuestos Generales del Estado, realizando una estricta aplicación de la doctrina general sobre subvenciones públicas.

Por un lado, se han ido limitando progresivamente las líneas de becas y ayudas cuya gestión se centralizará en el Ministerio de Educación (las denominadas becas y ayudas no territorializadas) que han quedado reducidas a las becas destinadas a alumnos que cursen estudios en la UNED y el CIDEAD, por tratarse de centros no presenciales dependientes de la Administración General del Estado, y a las becas que se concedan a

44 Voto particular a la Sentencia 188/2001 formulado por el Magistrado Carles Viver Pi-Sunyer.

45 Real Decreto 675/2008, de 28 de abril, por el que se establecen los umbrales de renta y patrimonio familiar y las cuantías de las becas y ayudas al estudio del Ministerio de Educación, Política Social y Deporte para el curso 2008-2009.

46 SSTC 91/1992 y 188/2001. 
alumnos de Ceuta y Melilla y de los centros españoles en el exterior. ${ }^{47}$ En realidad, se trata de programas que afectan a centros educativos sobre los que la Administración General del Estado ostenta la condición de Administración educativa, por lo que, en sentido estricto, no debería hablarse de una centralización de funciones educativas.

Todas las demás becas y ayudas (todas las que benefician a los estudiantes que cursan enseñanzas en el territorio de las Comunidades Autónomas) tienen la consideración de becas y ayudas territorializadas (quizás fuese más correcto denominarlas territorializables), en la medida en que los fondos que las financien podrían distribuirse entre la Comunidades Autónomas, que ejercerán las funciones ejecutivas a partir del momento en que asuman los correspondientes traspasos. En relación con estos programas, la jurisprudencia constitucional ha venido realizando una tarea de eliminación progresiva de funciones ejecutivas concretas que, de modo más o menos justificado, se reservaban a la gestión centralizada del ministerio. ${ }^{48}$ Estos pronunciamientos se recogen en el Real Decreto $1721 / 2007^{49}$, que contempla que a partir del momento en que suscriba el acuerdo de traspaso de estas funciones, las administraciones educativas asumirán íntegramente la gestión de estos programas de becas y ayudas $\mathrm{y}$, concretamente, ejercerán las siguientes funciones:

- Aprobarán y publicarán las convocatorias de becas y ayudas antes del inicio de cada curso escolar.

— Las solicitudes deberán dirigirse a las Comunidades Autónomas en las que radique el domicilio familiar del interesado o, en el caso de enseñanzas no presenciales, en la Administración educativa de la que dependa el centro que las imparta.

— La resolución y pago corresponderá a la comunidad autónoma convocante, tanto en lo que se refiere a la cantidad fija, como a la cantidad variable que se asignará al finalizar el proceso.

Tanto las convocatorias como las resoluciones deberán hacer constar expresamente que se trata de programas financiados con cargo a los Presupuestos Generales del Estado.

${ }^{47}$ En este sentido, la STC 25/2015 ha declarado inconstitucional que la Administración General del Estado se reserve la gestión centralizada de las becas de movilidad, «destinadas a cursar estudios en comunidad autónoma distinta a la del domicilio familiar del estudiante».

48 El último pronunciamiento en este sentido ha sido la STC 95/2016, que considera inconstitucional la atribución a órganos de la Administración General del Estado de las facultades de resolución y pago a los beneficiarios del componente variable de las becas generales.

49 El Real Decreto 1721/2007, de 21 de diciembre, por el que se establece el régimen de las becas y ayudas al estudio personalizadas, tenía como objetivo expresamente declarado en el preámbulo «dar cumplimiento a la jurisprudencia del Tribunal Constitucional en esta materia y concretamente a la recogida en las Sentencias 188/2001, de 20 de septiembre y Sentencia 212/2005, de 21 de julio, todo ello manteniendo la eficacia y eficiencia del sistema». Concretamente, se dedica a este fin el Capítulo V (artículos 39 a 42).

No obstante, la adecuación distó de ser perfecta, a juicio del Tribunal Constitucional, que ha dictado varias sentencias sobre su contenido que han motivado modificaciones puntuales de esta disposición, la última de las cuales ha sido el Real Decreto 293/2016, que ha tratado de adecuar la gestión del componente variable de las becas a la STC 95/2016. 
Las funciones ejecutivas reservadas al Ministerio de Educación se limitan exclusivamente a la potestad de calcular los parámetros necesarios para la aplicación de la fórmula que permite la asignación del componente variable, correspondiendo a las Comunidades Autónomas la aplicación de la misma al caso concreto y, por supuesto, la tramitación, resolución y pago de los expedientes, para la distribución de las cantidades a los becarios. ${ }^{50} \mathrm{La}$ centralización de esta función ejecutiva es imprescindible para garantizar la igualdad de los ciudadanos en el acceso a la educación en todo el territorio nacional y, además, sólo puede ser ejercida por la Administración General del Estado, ya que su cálculo se realizará a partir de la información obtenida del conjunto de solicitudes formuladas en el territorio del Estado.

Como es conocido, el traspaso del pleno ejercicio de las competencias a cada comunidad autónoma se producirá a partir de la fecha que se establezca en el Acuerdo de la Comisión Mixta por el que se apruebe el traspaso de las funciones, medios y servicios necesarios para la asunción de estas competencias. ${ }^{51}$

El proceso de descentralización de las competencias en materia de educación se completó en 2000 con la aprobación de los traspasos de medios a todas las Comunidades Autónomas. A partir de esta fecha únicamente quedaron pendientes de traspaso tres funciones concretas en materia educativa: la gestión del profesorado que imparte las enseñanzas de la materia de religión ${ }^{52}$, las funciones ejecutivas relacionadas con los procedimientos de homologación y convalidación de títulos y estudios extranjeros ${ }^{53}$ y la gestión de las becas y ayudas al estudio.

${ }^{50}$ La STC 95/2016 ha considerado que carece de justificación constitucional que el Ministerio de Educación se reserve la competencia de la asignación definitiva de la cuantía variable de la beca a los beneficiarios. En cumplimiento de este fallo, el Real Decreto 293/2016 ha modificado el Real Decreto $1721 / 2007$ reconociendo a las administraciones educativas la potestad para asignar la cuantía variable mediante la aplicación de la formula prevista en el artículo 9.2, reservándose el Ministerio de Educación, únicamente la determinación de los parámetros de la fórmula, cuyo cálculo deriva del análisis del conjunto de las solicitudes presentadas en el conjunto del territorio nacional.

${ }^{51}$ El régimen jurídico de los traspasos de funciones y servicios se recoge en los artículos 16 a 21 de la Ley 12/1983, de 14 de octubre, del proceso autonómico. En todo caso, para evitar eventuales dudas interpretativas, se recoge esta regla general de forma expresa en el apartado 1 de la disposición adicional cuarta del Real Decreto 1721/2007.

52 Entre 1999 y 2002 se traspasaron a 11 Comunidades Autónomas la gestión de los profesores de religión. En 2005 se acordó el traspaso a Asturias. En 2011 se acordó el traspaso al País Vasco. Actualmente se encuentra pendiente de traspaso el profesorado destinado en cuatro Comunidades Autónomas: Aragón, Andalucía, Canarias y Cantabria.

${ }^{53}$ En 2008 se iniciaron las negociaciones dirigidas a traspasar las funciones de homologación y convalidación de títulos y estudios extranjeros, que inicialmente quedaron limitadas a los estudios extranjeros de carácter no universitario. Se ha realizado el traspaso a las Comunidades Autónomas de Galicia (Real Decreto 1319/2008, de 24 de julio), Cataluña (Real Decreto 1385/ 2008, de 1 de agosto) y País Vasco (Real Decreto 893/2011, de 24 de junio). A partir del inicio de sus efectos, los órganos competentes de estas Comunidades Autónomas dictarán las resoluciones de homologación y convalidación de estos estudios, de acuerdo con los criterios generales y tablas de correspondencia elaboradas por el Ministerio de Educación. 
Lógicamente, en tanto no se apruebe el traspaso de estas funciones y servicios, las competencias ejecutivas sobre los programas de becas y ayudas territorializadas que se atribuyen a las comunidades autónomas corresponderán al Ministerio de Educación. ${ }^{54}$ Hasta el momento, la Comunidad Autónoma del País Vasco es la única que, desde los años ochenta, tiene asumidas las funciones en materia de becas y ayudas al estudio. $^{55}$

\section{SOBRE UNA POSIBLE REVISIÓN DEL FUNDAMENTO Y ALCANCE DE LA COMPETENCIA ESTATAL}

El legislador estatal parece haber renunciado a abordar la armonización y coordinación de los programas de ayudas a la enseñanza, mediante el establecimiento de un marco jurídico común. De hecho, a pesar de que se acuña legalmente la expresión Sistema Estatal de Becas y Ayudas al estudio, no se aborda en ninguna disposición jurídica ni su definición, ni la delimitación de su alcance, ni siquiera la identificación de los programas que comprende. La norma que más se aproximaría a este objetivo es el Real Decreto 1721/2007, que recoge los elementos estructurales básicos de determinadas prestaciones económicas que describen como becas y ayudas al estudio personalizadas.

Probablemente, una de las causas de situación normativa sea el tratamiento que el Tribunal Constitucional ha dado a las competencias en materia de becas y ayudas al estudio, estableciendo que las relaciones entre Administración General del Estado y Comunidades Autónomas en este ámbito deben adecuarse al esquema bases estatales/desarrollo normativo y ejecución autonómica. Esta doctrina que ha construido el Tribunal Constitucional se basa en dos argumentos esenciales. En primer lugar, la consideración de las becas como una especie de subvenciones públicas, lo que determina su sometimiento a la doctrina general sobre subvenciones recogida en la STC 13/1992. Pero también, y sobre todo, se basa en la aplicación de la regla 30. a del artículo 149.1 CE, que atribuye al Estado competencias normativas básicas, en detrimento de la regla 1. ${ }^{a}$ del mismo artículo.

54 Apartado 2 de la disposición adicional cuarta del Real Decreto 1721/2007.

55 Las funciones en materia de becas y ayudas en el ámbito de las enseñanzas no universitarias fueron asumidas mediante el Real Decreto 3195/1980, de 30 de diciembre, por el que se completa el traspaso de Servicios del Estado a la Comunidad Autónoma del País Vasco en materia de enseñanza, que traspasa las funciones y servicios que en el ámbito de la Comunidad Autónoma del País vasco corresponden, entre otros, al Instituto Nacional de Asistencia y promoción del Estudiante.

La funciones en materia de becas y ayudas en al ámbito universitario fueron asumidas mediante el Real Decreto 1014/1985, de 25 de mayo, sobre traspaso de funciones y servicios del Estado a la Comunidad Autónoma del País Vasco en materia de universidades, que traspasa «la regulación y gestión de las convocatorias de becas para estudiantes de enseñanza superior, con vecindad administrativa en el País Vasco», precisando que «dichas convocatorias se realizarán respetándose los criterios básicos que se establezcan para todo el Estado». 
A nuestro juicio, resultaría conveniente revisar ambas premisas y, como consecuencia de ello, podría legitimarse el reconocimiento de un nuevo fundamento de la competencia estatal, que comprendería potestades normativas de extensión e intensidad diferentes a las que actualmente se ejercen.

\subsection{La naturaleza prestacional de las ayudas al estudio.}

Ayuda y subvención no son términos sinónimos empleados indistintamente para aludir a una misma institución. Las ayudas constituyen un género más amplio, del cual las subvenciones son una especie, quizás la más frecuente y conocida y, desde luego, la más profusamente regulada. El propio articulado y las definiciones que contiene, refrendan que la LGS (2003) no regula las ayudas públicas en general, sino una peculiar clase de ayudas, a las que se denomina subvenciones. ${ }^{56}$

Desde una perspectiva administrativa, las subvenciones son «una técnica de fomento de determinados comportamientos considerados de interés general e incluso un procedimiento de colaboración entre la Administración pública y los particulares para la gestión de actividades de interés público». ${ }^{57}$ Sin embargo, parece haber unanimidad en que «la subvención ni es la única técnica de fomento, ni es exclusivamente una técnica de fomento». ${ }^{58}$

Ya hemos visto que el legislador español ha eludido un pronunciamiento general y expreso sobre la naturaleza jurídica de las becas y ayudas al estudio, aunque implícitamente ha optado por calificarlas como subvenciones públicas, basándose en sus indudables similitudes con esta institución.

Esta calificación jurídica de las ayudas a los estudiantes constituye una premisa de capital importancia, ya que ha condicionado el tratamiento jurídico que reciben, tanto en la doctrina del Tribunal Constitucional, como en la normativa vigente. Sin embargo, debe advertirse que esta premisa ha sido cuestionada por la doctrina científica e incluso, por una parte del Tribunal Constitucional, que ha desarrollado una posición minoritaria en este sentido. Concretamente, dos de los votos particulares a las sentencias $188 / 2001^{59}$ y $212 / 2005^{60}$, suscritos por cuatro de los Magistrados, sostienen que resulta incorrecto equiparar el singular sistema de asistencia o de com-

56 PASCUAL GARCÍA, José. «Régimen jurídico de las subvenciones públicas». Estudios Jurídicos. Boletín Oficial del Estado. 5. a edición (2008). Pág.47.

57 Exposición de motivos de la LGS (2003).

58 SESMA SANCHEZ, Begoña. «Las subvenciones públicas». Lex Nova. 1998. Pág. 30.

59 Voto particular formulado por el Magistrado don Vicente Conde Martín de Hijas, al que se adhirieron los Magistrados don Manuel Jiménez de Parga y Cabrera y don Fernando Garrido Falla; y voto particular fue formulado por el Magistrado don Guillermo Jiménez Sánchez.

60 En esta sentencia se reproduce el contenido de los votos recogidos citados en relación con la STC 188/2001, elaborados por los mismos magistrados: Voto particular que formula el Magistrado don Vicente Conde Martín de Hijas, al que se adhieren los Magistrados don Roberto García-Calvo y Montiel y don Jorge Rodríguez-Zapata Pérez; y voto particular fue formulado por el Magistrado don Guillermo Jiménez Sánchez. 
plemento de la capacidad económica que suponen las becas y ayudas para el estudio a otras ayudas o subvenciones financieras encuadrables en el campo de las clásicas medidas de fomento de determinadas actividades de índole o naturaleza patrimonial, como sería el caso de las otorgables a determinadas explotaciones agrarias, instalaciones industriales u organizaciones comerciales o, incluso, dada su finalidad última de facilitar el desarrollo de una actividad ordenada a la prestación de un servicio público, de las que pudieran instrumentarse para favorecer el establecimiento o la mejora de centros docentes.

Los principales argumentos que pueden aportarse para justificar la distinción entre las becas y las subvenciones son los siguientes: ${ }^{61}$

- En primer lugar, ambas figuras persiguen fines diferentes. La finalidad última de las becas o ayudas para el estudio no es promover una determinada actividad o comportamiento de los beneficiarios, que se considera que contribuye al interés general (como hacen las subvenciones), sino que se dirigen, esencialmente, a posibilitar o facilitar el efectivo ejercicio de un derecho fundamental de tan relevante significación en el proceso de asegurar la igualdad entre los ciudadanos españoles como, sin duda, es el derecho a la educación. En decir, las ayudas a la educación atienden a la financiación de aquellos servicios educativos cuya adquisición o provisión no se financia directamente con gasto público, de modo que sus costes deben ser (al menos inicialmente) sufragados por las familias. Nos movemos aquí en campos singularmente transcendentes, en la esfera propia de los principios de igualdad de oportunidades y de libre desarrollo de la personalidad, el último de los cuales constituye uno de los fundamentos del orden político y de la paz social (artículo 10.1 CE).

- En segundo lugar, el perfil de los beneficiarios de becas y subvenciones no coinciden. Los destinatarios de los apoyos económicos que representan las becas o las ayudas para el estudio no son los Centros docentes, los establecimientos prestadores del servicio público de la educación (esto es, si se quiere, las instituciones a través de las cuales se desarrolla o actúa la actividad docente, la enseñanza), sino que, en rigor, los destinatarios de las becas o las ayudas al estudio, los becarios o beneficiarios, son los escolares, alumnos o discentes, en su condición o carácter de titulares últimos del derecho fundamental a la educación.

El ámbito de aplicación de estas ayudas comienza donde desaparece la garantía de gratuidad de la enseñanza, resultando su presencia más intensa en aquellos niveles educativos en los que existe un mayor porcentaje de gasto privado, como son educación infantil, Bachillerato, Formación Profesional y, sobre todo, la educación universitaria, es decir, las enseñanzas no obligatorias.

${ }^{61}$ Los dos primeros argumentos fueron esbozados por JIMENEZ SÁNCHEZ, en su voto particular a la STC 188/2001. 
- En tercer lugar, las subvenciones tienen un marcado carácter selectivo, mientras que las ayudas al estudio excluyen habitualmente la competencia entre los solicitantes, reconociéndose la condición de beneficiario a todos aquellos que reúnan los requisitos socioeconómicos y académicos que se establezcan. Es más, las ayudas al estudio, especialmente en la Educación Básica, tienen una marcada vocación de universalidad, es decir, de extender progresivamente su cobertura a todos los estudiantes que cursen estas etapas educativas.

Esta diferencia tiene su reflejo jurídico en el procedimiento de otorgamiento de las ayudas. El procedimiento ordinario de concesión de subvenciones se tramitará en régimen de concurrencia competitiva, que requiere la comparación de las solicitudes presentadas, a fin de establecer una prelación entre las mismas de acuerdo con los criterios de valoración previamente fijados en las bases reguladoras y en la convocatoria, y adjudicar, con el límite fijado en la convocatoria dentro del crédito disponible, aquellas que hayan obtenido mayor valoración en aplicación de los citados criterios. ${ }^{62}$ La concesión directa se contempla, pero reservada a supuestos marcadamente excepcionales. ${ }^{63}$

Sin embargo, como hemos señalado, la mayor parte de las becas y ayudas al estudio son objeto de concesión directa y se aprecia una creciente tendencia a implantar en los restantes programas esta modalidad de concesión en detrimento de los procedimientos de concurrencia competitiva. ${ }^{64}$

- Finalmente, la tipología de las prestaciones no son coincidentes. Atendiendo a la literalidad de la LGS (2003), únicamente podrían calificarse como subvenciones en sentido estricto aquellas ayudas al estudio que supongan una transferencia dineraria desde la Administración hacia los estudiantes y sus familias. Sin embargo, no encontrarían encaje en esta institución otras prestaciones que, o bien tienen carácter dinerario, pero se entregan directamente a las instituciones educativas (así, por ejemplo, las universidades reciben directamente la compensación económica correspondiente a la exención del pago de precios públicos que se reconoce a los estudiantes matriculados en sus titulaciones oficiales), o bien consisten en servicios (como podrían ser la asistencia sanitaria que se dispensa a los alumnos a través del seguro escolar, los servicios de préstamo de libros de texto o la asistencia alumnos con necesidades educativas especiales).

De este modo, consideramos que las becas y ayudas a los estudiantes son indudablemente una ayuda, pero su naturaleza no es subvencional, sino que se aproxima

${ }^{62}$ Artículo 22.1 LGS (2003).

${ }^{63}$ Artículo 22.2 LGS (2003).

${ }^{64}$ Esta tendencia se viene observando en los últimos cursos, por ejemplo, en muchos programas de apoyo a la gratuidad de libros de texto promovidos por las Administraciones educativas en el ámbito de la Educación Básica. 
mucho más a otras prestaciones económicas que se encuentran expresamente excluidas del ámbito de aplicación de la ley de subvenciones, con las que podrían fácilmente equipararse. $^{65}$

Ciertamente, el Tribunal Constitucional no está vinculado por las decisiones del legislador, pero resulta indudable que la configuración legal de las ayudas al estudio proporciona al Alto Tribunal un punto de partida para sus razonamientos. En este sentido, a nuestro juicio, podrían adoptarse dos modificaciones legales que, además de mejorar la calidad y eficacia del sistema, permitirían fundamentar una revisión de su encaje competencial:

- Por un lado, sería razonable dispensar a las ayudas al estudio un tratamiento singular, como una prestación económica vinculada a la prestación del servicio público de la educación, de similar naturaleza, por ejemplo, a las prestaciones económicas reguladas en el artículo 17 de la LDP (2006) ${ }^{66}$, que consisten en una entrega de fondos públicos sin contraprestación, pero no tienen la consideración legal de subvención, aunque se encuentran en la frontera. ${ }^{67}$ Para ello, bastaría con incluir expresamente las becas y ayudas al estudio en el artículo 2.4 de la LGS (2003). ${ }^{68}$ Esta modificación legal no entraría en contradicción directa con los pronunciamientos del Tribunal Constitucional, que tienen cierto cuidado en declarar que se aplica a las becas el régimen competencial de las subvenciones, pero sin afirmar de forma explícita que las becas son subvenciones.

Debe advertirse que el legislador autonómico ya ha tratado de excluir a las becas y ayudas al estudio del ámbito de aplicación de la LGS (2003) ${ }^{69}$, si bien consideramos que esta declaración general corresponde al legislador estatal de conformidad con las reglas $13 .^{\mathrm{a}}, 14 .^{\mathrm{a}}$ y $18 .^{\mathrm{a}}$ del art $149.1 \mathrm{CE}$, que otorgan al Estado las competencias en materia de bases y coordinación

65 Véase el apartado 4 del artículo 2 LGS (2003).

${ }^{66}$ Ley 39/2006, de 14 de diciembre, de Promoción de la Autonomía Personal y Atención a las personas en situación de dependencia.

67 PASCUAL GARCÍA, José. «Régimen jurídico de las subvenciones públicas». Estudios Jurídicos. Boletín Oficial del Estado. 5. a edición (2008). Pág. 52.

${ }^{68}$ El apartado 4 del artículo 2 de la LGS (2003) recoge una relación de ayudas y prestaciones económicas que no tienen la condición de subvención y que, por ello, quedan excluidas del ámbito de aplicación de esta ley.

69 Valga por todas la Ley 10/2016, de 1 de diciembre, de medidas de emergencia en relación con las prestaciones económicas del Sistema Público de Servicios Sociales y con el acceso a la vivienda en la Comunidad Autónoma de Aragón, cuyo artículo 3 establece que:

1. Las prestaciones económicas del Sistema Público de Servicios Sociales son aportaciones dinerarias con un régimen jurídico propio, definidas por su carácter finalista, requisitos y condiciones de reconocimiento, y carecen de la consideración de subvenciones públicas.

2. La misma naturaleza tendrán las prestaciones económicas de carácter social incluidas en el Catálogo de Servicios Sociales de la Comunidad Autónoma de Aragón y en los de las entidades locales. 
general de la planificación económica, Hacienda general y procedimiento administrativo común. ${ }^{70}$

- Por otra parte, podría configurarse un derecho subjetivo de los estudiantes a obtener las prestaciones económicas que comprende el Sistema Estatal de becas y ayudas al estudio, al que se acceda al acreditarse el cumplimiento de determinados requisitos socioeconómicos (umbrales de renta y patrimonio familiar) y académicos. ${ }^{71}$ Esta configuración jurídica podría asimilarse a la que se establece para el derecho a la atención de las situaciones de dependencia, que el Tribunal Constitucional ha considerado adecuada para fundamentar la aplicación de la regla $1 .^{a}$ del artículo 149.1 CE. ${ }^{72}$

A nuestro juicio, esta regulación estatal debería tener el carácter de ley orgánica en aplicación del artículo 81.1 CE, que reserva a estas normas el desarrollo de los derechos fundamentales y de las libertades públicas. Y ello, a pesar de la doctrina del Tribunal Constitucional que declara que la reserva material debe interpretarse restrictivamente, de manera que sólo requerirá Ley orgánica la regulación que desarrolle la Constitución de manera directa y en elementos esenciales para la definición del derecho fundamental, ya sea una regulación directa, general y global del mismo o en una parcial o sectorial, pero, igualmente, relativa a aspectos esenciales del derecho, y no, por parcial, menos directa o encaminada a contribuir a la delimitación y definición legal del derecho. ${ }^{73}$

\subsection{La reivindicación de la regla 1. ' del artículo 149.1.1. ' de la Constitución}

Ciertamente, la potencial intensidad de las potestades estatales amparadas por el artículo 149.1.1. ${ }^{a}$ CE ha llevado al Tribunal Constitucional a mostrar extrema cautela para legitimar la invocación estatal de este título habilitante, consciente de que su utilización abusiva podría conducir a una extralimitación de las competencias estatales, más allá de los límites establecidos en el artículo 149.1 de la Constitución. No obstante, esta necesaria prudencia no puede conducir al vaciamiento de este títu-

${ }^{70}$ Este precepto ha sido objeto de recurso de inconstitucional promovido por el Presidente del Gobierno.

En este sentido, se comparte el criterio manifestado por el Consejo de Estado, en su dictamen 639/2017, de 20 de julio.

${ }^{71}$ Algunos sectores sostienen que la disposición adicional novena de la LIP (2005) ya configura un derecho subjetivo a obtener becas. Sin embargo, se trata de una afirmación poco fundada jurídicamente, ya que dicha norma se limita a aplicar el procedimiento de concesión directa previsto en la LGS (2003) a determinadas líneas de ayudas al estudio (las que no se convoquen con un número predeterminado de beneficiarios).

72 STC 18/2016, de 4 de febrero, FJ. 7.

73 En este sentido se pronunció STC 6/1982, referida al derecho de educación, pero también SSTC 67/1985, 140/1986, 160/1987 y 127/1994, en relación con otros derechos fundamentales. 
lo competencial, que privaría al Estado de un instrumento esencial para garantizar la igualdad de los ciudadanos y la unidad de la Nación, principios ambos constitucionalmente salvaguardados. La necesidad de conciliar ambos principios, ha llevado al Tribunal Constitucional a someter la aplicación de este precepto a condiciones estrictas que pretenden evitar que quede «desbordado el ámbito y sentido del artículo 149.1.1. ${ }^{\circ} \mathrm{CE}$, que no puede operar como una especie de título borizontal, capaz de introducirse en cualquier materia o sector del ordenamiento por el mero becho de que pudieran ser reconducibles, siquiera sea remotamente, hacia un derecho o deber constitucional». ${ }^{74}$

Entendemos que la eventual calificación legal de las ayudas al estudio como una prestación de carácter económico del Sistema Educativo orientada a garantizar la igualdad en el ejercicio del derecho, por un lado, y el desarrollo por el Tribunal Constitucional de principios y criterios que permiten la aplicación prudente del artículo 149.1.1. ${ }^{\text {a }} \mathrm{CE}$, por otro, proporcionan argumentos para promover una revisión del fundamento constitucional de la competencia estatal en materia de becas y ayudas al estudio, y ofrecen garantías suficientes frente a los eventuales riesgos de abuso que pudieran derivarse de este nuevo encuadre constitucional.

Para afrontar esta tarea resultará necesario abordar sucesivamente dos cuestiones: en primer lugar, si la submateria becas y ayudas al estudio tiene cabida en la materia descrita por el artículo 149.1.1. a CE y, en este caso, cuál sería el alcance de las potestades que este título confiere al Estado.

- La primera cuestión consiste en delimitar con precisión el contenido de la materia a que se refiere esta regla $10^{\mathrm{a}}$ del artículo $149.1 \mathrm{CE}$, que se describe como «las condiciones básicas que garanticen la igualdad de los españoles en el ejercicio de los derechos (...) constitucionales». El Tribunal Constitucional proporciona los siguientes criterios sobre el alcance de esta expresión:

- En primer lugar, se afirma taxativamente que «el artículo 149.1.1. ${ }^{\circ}$ CE sólo presta cobertura a aquellas condiciones que guarden una estrecha relación, directa e inmediata, con los derechos que la Constitución reconoce». ${ }^{75}$ La literalidad de la norma no sugiere una interpretación restrictiva de los derechos constitucionales, de modo que podría sostenerse que se está haciendo referencia a todos los derechos mencionados en la Constitución o, al menos, a todos los recogidos en el título I. ${ }^{76}$ En cualquier caso, siguiendo el criterio de prudencia que nos hemos impuesto y adoptando la interpretación más restrictiva, deben considerarse incluidos, al menos, los derechos contenidos en la sección 1. ${ }^{a}$ del capítulo 2. ${ }^{a}$ del título I, merecedores del mayor

${ }^{74}$ STC 61/1997, reiterada por STC 228/2003, de 18 de diciembre, F. 10.

75 STC 61/1997, reiterada por STC 228/2003, de 18 de diciembre, F. 10.

${ }^{76}$ Los más recientes pronunciamiento del Tribunal Constitucional parece extender su aplicación a todos los derechos del Título I, al incluir expresamente a los principios rectores de la política social y económica(STC 33/2014, de 27 de febrero, FJ 4; STC 18/2016, de 4 de febrero, FFJJ 7 y 8, STC 18/2017, de 2 de febrero, FJ 4) 
grado de protección, entre los se encuentra el derecho fundamental a la educación.

- En segundo lugar, a pesar de los titubeos iniciales del Tribunal Constitucional, resulta claro que las condiciones básicas se refieren a los elementos esenciales de los derechos y no pueden interpretarse como sinónimo de normas básicas o de bases estatales.

En su lugar, se exige que estas condiciones básicas hagan «referencia al contenido primario (STC 154/1988) del derecho, a las posiciones jurídicas fundamentales (facultades elementales, limites esenciales, deberes fundamentales, prestaciones básicas, ciertas premisas o presupuestos previos.)». Dentro de esas «condiciones básicas» cabe entender incluidos asimismo aquellos criterios que guardan una relación necesaria e inmediata con aquéllas, tales como el objeto o ámbito material sobre el que recaen las facultades que integran el derecho (...); los deberes, requisitos mínimos o condiciones básicas en que ba de ejercerse un derecho (...); los requisitos indispensables o el marco organizativo que posibilitan el ejercicio mismo del derecho, etcétera». ${ }^{77}$

- Finalmente, es preciso que la actuación estatal que pretenda ampararse en este título sirva al objetivo de garantizar la igualdad de todos los españoles. ${ }^{78}$ En todo caso, debe advertirse que el propio concepto de igualdad admite discrepancias: el Tribunal Constitucional ha venido señalando que la igualdad a garantizar con el establecimiento de condiciones básicas comunes no puede consistir en una igualdad formal absoluta ${ }^{79}$, mientras que otros autores consideran que la admisión de modulaciones autonómicas atenta contra el mismo principio de igualdad. ${ }^{80}$

Es decir, para que las becas y ayudas al estudio puedan incardinarse en el artículo 149.1.1. ${ }^{a} \mathrm{CE}$ deben verificarse tres premisas. Primero, que exista un derecho fundamental o libertad pública involucrado, que en este caso es el derecho a la educación consagrado en el artículo $27 \mathrm{CE}$. Segunda, que el objeto de la actuación estatal se refiera al contenido primario de este derecho. Y tercera, que persigan garantizar la igualdad de los españoles en su disfrute. No resulta difícil verificar el cumplimiento de estas premisas en el Sistema Estatal de Becas y Ayudas al estudio, que comprende prestaciones de carácter económico dirigidas a remover los obstáculos que impidan u obstaculicen la igualdad material en el ejercicio del derecho a la educación.

77 STC 61/1997, FJ. 8.

78 En este mismo sentido, entre otras, STC 133/2006, FJ. 3.

79 STC 188/2001, FJ 12.

${ }^{80}$ Voto particular que formula el Magistrado don Vicente Conde Martín de Hijas respecto de la STC 188/2001, al que se adhieren los Magistrados don Manuel Jiménez de Parga y Cabrera y don Fernando Garrido Falla. 
- Una vez convenida la posibilidad de subsumir las becas y ayudas en el artículo 149.1.1. ${ }^{a} \mathrm{CE}$, es preciso establecer el alcance de las potestades que este precepto reserva al Estado. En principio, el tenor literal de la norma encomienda al Estado la regulación de estas condiciones básicas de los derechos constitucionales. Sin embargo, la naturaleza y alcance de esta potestad regulatoria admite diversas interpretaciones:

- La actual posición del Tribunal Constitucional constriñe las potestades estatales al ámbito normativo, reproduciendo el esquema de bases estatales y desarrollo legislativo autonómico. ${ }^{81}$ Es decir, se aprecia una equiparación entre condiciones básicas y normativa básica que, sin embargo, resulta discutible, invocando incluso doctrina constitucional anterior, que establece la diferencia entre ambas nociones. ${ }^{82}$

- En el otro extremo se sitúa la interpretación que otorgaría al Estado una competencia exclusiva plena en la materia. ${ }^{83}$ El propio Tribunal Constitucional admitió la legitimidad de amparar en la regla 1. ${ }^{a}$ no sólo competencias normativas, sino también ejecutivas, haciendo referencia a supuestos en los que la conexión con el derecho fundamental en cuanto a condición de igualdad se considera bastante más lejana que entre la beca y el ejercicio del derecho a la educación. ${ }^{84}$ En cualquier caso, la elemental prudencia que subyace en la doctrina del Tribunal Constitucional recomienda evitar esta interpretación, por excesivamente intrusiva en el campo de competencias autonómicas, que quedarían virtualmente excluidas.

Descartadas ambas posiciones, se impone la intermedia y, a nuestro juicio más razonable, que considera que nos encontramos ante una competencia legislativa plena. De este modo, la invocación de la regla 1. ${ }^{a}$ del artículo 149.1 CE supondría una modificación, quizás sutil, pero no irrelevante,

81 STC 188/2001, de 20 de noviembre, FJ.12, establece que:

En conclusión, según nuestra doctrina, el art. 149.1.1 CE «constituye un título competencial autónomo, positivo o habilitante, constreñido al ámbito normativo, lo que permite al Estado una regulación, aunque limitada a las condiciones básicas que garanticen la igualdad, que no el diseño completo y acabado de su régimen jurídico», por lo que «el art. 149.1.1 CE no debe ser entendido como una prohibición de divergencia autonómica» [STC 61/1997, FJ 7 b)].

82 STC 61/1997, FJ. 7.

83 Esta posición se reflejó en el Voto particular que formula el Magistrado don Vicente Conde Martín de Hijas respecto de la STC 188/2001, al que se adhieren los Magistrados don Manuel Jiménez de Parga y Cabrera y don Fernando Garrido Falla. Desde entonces, sus argumentos se han recogido en votos particulares a todas las sentencias dictadas sobre conflictos de competencias en materia de becas y ayudas al estudio.

${ }^{84}$ Nos referimos a las SSTC 64/1989 (FFJJ. 3 y 4) y 189/1989 (FJ. 3), referida a ayudas a empresas periodísticas y agencias informativas, amparadas en el derecho fundamental a la información. Más recientemente, STC 107/2014, de 26 de junio, acreditación de laborales por la ANECA. 
de la intensidad y extensión de la competencia estatal. Por un lado, aumentaría la intensidad de las potestades normativas estatales que, como contrapartida, se ejercerían sobre un ámbito material circunscrito a las condiciones básicas necesarias para asegurar la igualdad. ${ }^{85}$

En cualquier caso, debemos señalar que la regla $1 .^{a}$ del artículo $149.1 \mathrm{CE}$ constituye el título competencial prevalente del Estado, pero no el único, de modo que sería posible invocar otros preceptos constitucionales para justificar otras actuaciones estatales, normativas e, incluso, ejecutivas.

\section{CONCLUSIÓN}

Las becas y ayudas al estudio no constituyen subvenciones públicas, sino prestaciones financiadas con cargo a recursos públicos. De este modo, el reconocimiento del derecho a su obtención debería encontrarse excluido del ámbito de aplicación de la legislación general de subvenciones y debería regirse por un régimen jurídico específico, similar al diseñado para otros sistemas prestacionales como son los existentes en el ámbito de la Dependencia.

Correspondería al legislador estatal definir el contenido de este derecho a obtener ayudas al estudio y establecer las condiciones para su ejercicio, respetando los parámetros marcados por la doctrina del Tribunal Constitucional, que podemos resumir en los siguientes términos:

—En aplicación del artículo 81.1 CE, la legislación estatal debería tener el carácter de ley orgánica, aunque la interpretación restrictiva de la extensión de esta reserva material que impone el Alto Tribunal supondrá que la regulación de determinados aspectos del Sistema Estatal de becas y ayudas al estudio se aborde mediante ley ordinaria.

- La extensión de la reserva orgánica debe fijarse en conexión con el marco constitucional y estatutario de distribución de competencias, ya que el artículo 81.1 CE no contiene, en puridad, ningún título competencial habilitante a favor del Estado. En la práctica, lo más relevante para la resolución del conflicto no radica tanto en la distinción entre la naturaleza jurídica de la reserva de ley y las reglas de competencia, cuanto en la delimitación del alcance material de la reserva de ley orgánica y en la determinación de en qué medida esta delimitación debe hacerse o no a partir del sistema de

${ }^{85}$ En todo caso, la STC 18/2016 (FJ. 7) realiza una generosa interpretación del ámbito material sobre el que pueden proyectarse las potestades normativas en relación con el derecho a la atención en situaciones de dependencia, que podría trasladarse a un eventual derechos a la obtención de becas y ayudas al estudio, en caso de procederse a su configuración legal. 
distribución de competencia. ${ }^{86}$ En este caso, el legislador estatal, al amparo del artículo 149.1.1. ${ }^{\circ} \mathrm{CE}$, podría regular el contenido primario del derecho subjetivo a la obtención de prestaciones del Sistema Estatal de becas y ayudas al estudio, en la medida en que persiguen garantizar la igualdad de los ciudadanos en el acceso y ejercicio del derecho fundamental a la educación. Aunque el alcance de esta potestad normativa deberá ser perfilado por el Tribunal Constitucional, entendemos comprendido en el mismo, al menos, la definición de un catálogo de prestaciones básicas que atiendan a la provisión de los bienes y servicios educativos, y los requisitos mínimos comunes para el acceso a las diferentes prestaciones.

— Finalmente, el contenido de este régimen jurídico estatal debería respetar los principios constitucionales que resulten de aplicación a los programas de ayudas al estudio promovidos por los poderes públicos.

Title:

State competence on student grants: basis and scope.

\section{Summary:}

1. Public funding of education. 2. The right to obtain grants. 2.1. Constitutional or legal nature of the right. 2.2. Content and constitutional limits of the right. 3. The student grants system. 3.1. Concept, characteristics of student grants. 3.2. Nature of student grants. 4. The territorial distribution of competences related to grants. 4.1. Regulatory power. 4.2. Executive powers. 5. A possible revision of basis and scope of competence. 5.1. Grants as public service. 5.2. The rule 1 of article 149.1 of the Constitution. 6. Conclusions.

\section{Resumen:}

Las becas y ayudas al estudio vienen siendo calificadas en el ordenamiento español como subvenciones públicas. Este trabajo sostiene que sería más adecuado con nuestro marco constitucional otorgarles la consideración de prestaciones públicas, financiadas con cargo a los Presupuestos Generales del Estado. La revisión de la naturaleza jurídica de las becas y ayudas al

${ }^{86}$ MESEGUER YEBRA, Joaquín. «Ámbito material reservado a la Ley Orgánica y su consideración como norma competencial de atribución competencial (a propósito de la STC 173/1998, de 23 de julio)», en Revista Jurídica de la Comunidad de Madrid, n. ${ }^{\circ}$. Madrid, 1999. Pág. 3. 
estudio tendría relevantes consecuencias: por un lado, recomendaría que el Legislador definiese el contenido del derecho a obtener estas prestaciones públicas, de forma similar a otros ámbitos de la actuación administrativa. Por otra parte, permitiría fundamentar la revisión de la doctrina del Tribunal Constitucional sobre el reparto de las competencias entre el Estado y las Comunidades Autónomas en esta materia, a partir de la invocación de la regla $1 .{ }^{a}$ del artículo 149.1 CE.

\begin{abstract}
:
Scholarships are classified in the Spanish legal system as public subsidies. This paper argues that it would be more appropriate with our constitutional framework to confer them the consideration of public benefits, financed by Publics Budgets. The review of the legal nature of student grants would have important consequences: on the one hand, Law should rule the content of the right to obtain these public benefits, in a similar way to other areas of Administration. On the other hand, the Constitutional Court may review its position on the distribution of the competences between the State and the Autonomous Regions, by calling the rule 1 of article 149.1 of the Constitution.
\end{abstract}

\title{
Palabras clave:
}

Becas y ayudas al estudio. Derecho a la educación. Competencias en materia educativa.

Key words:

Student grants. Education rights. Competences in educational matters. 